JOURNAL Of CONTEMPORARY INDONESIAN ART

Jurusan Seni Murni

FSR ISI Yogyakarta

ISSN: 2442-3394

E-ISSN: 2442-3637

\title{
MEMOAR PENYAKIT MENTAL DALAM SENI LUKIS
}

\section{Oleh: Elisa Faustina}

Institusi: Institut Seni Indonesia Yogyakarta

Jalan Parangtritis Km. 6,5 Sewon Yogyakarta

E-mail: elisa.faustina@yahoo.com

\begin{abstract}
ABSTRAK
Sepanjang sejarah seni, telah banyak seniman yang berkarya seni dari pengalaman penyakit mentalnya. Penyakit mental sendiri berarti ketidakmampuan individu untuk beraktivitas karena gangguan signifikan klinis secara psikologis. Gejala penyakit mental seringkali tidak terdeteksi sebab kerap kali tersamarkan sebagai imajinasi bagi seniman. Di sisi lain, karya seni menjadi perekam akan pengalaman hidup pembuatnya. Memoar penyakit mental divisualisasikan dalam lukisan dengan warna-warna berintensitas tinggi dan bentuk-bentuk ganjil. Bentuk dan objek yang disajikan bersifat nanar dan ambigu, dengan kecenderungan surealistik. Untuk menyuarakan kelimbungan yang dialami dalam penyakit mental. Lukisan akan lebh banyak membawakan suasana dalam karya. Sebab penyakit mental sendiri adalah pengalaman yang tidak jelas batas-batasnya. Penyakit mental masih memiliki stigma dalam masyarakat. Lewat karya lukis, konflik internal dalam kehidupan seseorang dapat didiskusikan. Lukisan menjadi salah satu media pembebasan bagi nilai-nilai konvensional. Pengemasan ide dan gagasan secara kreatif melalui nilai-nilai estetika, memberikan pandangan dan pengalaman baru bagi audiens agar dapat menghargai mereka dengan penyakit mental.
\end{abstract}

Kata Kunci: Penyakit Mental, Terapeutik, Katarsis, Otobiografis, Memoar

\begin{abstract}
Throughout the history of art, there have been many artists who created art from the experience of mental illness. Mental illness itself means the inability of an individual to perform activities due to psychologically significant clinical disorders. Symptoms of mental illness often go undetected because they are often disguised as an artist's imagination. On the other hand, the work of art becomes a recorder of the creator's life experience. Mental illness memoirs are visualized in paintings with high intensity colors and odd shapes. The shapes and objects presented are vague and ambiguous, with a surrealistic tendency. To speak out about the distress experienced in mental illness. Painting will bring more atmosphere to the work. Because mental illness itself is an experience with no clear boundaries. Mental illness still has a stigma in society. Through painting, internal conflicts in a person's life can be discussed. Painting is one of the liberating media for conventional values. Creative packaging through aesthetic values, provides new perspectives and experiences for the audience to appreciate those with mental illness.
\end{abstract}

Keyword: Mental Illness, Therapeutic, Catharsis, Autobiographical, Memoirs 


\section{A. Pendahuluan}

Untuk berkarya seni, penulis sangat meyakini bahwa latar belakang pengalaman memberikan kesadaran dalam kesenian sebagai inspirasi pengkaryaan yang paling baik. Penulis memiliki pengalaman mendapatkan penanganan dan perawatan sebagai konsumen (penderita) masalah kesehatan mental.

Menurut berbagai sumber disebut juga mental disorder, gangguan mental, gangguan kejiwaan, penyakit kejiwaan, dengan penderitanya disebut ODMK (Orang dengan Masalah Kesehatan Mental). Dalam buku Psikologi Abnormal, disebutkan sebagai: "Perilaku klinis yang signifikan, sindrom psikologis, atau pola yang terjadi pada seseorang yang dihubungkan dengan tekanan yang sedang terjadi seperti gejala yang menyakitkan, ketidakmampuan (seperti tidak berfungsinya satu atau dua area penting), atau dengan peningkatan risiko yang signifikan terhadap kematian, rasa sakit, ketidakmampuan, atau suatu kehilangan kebebasan. Sebagai tambahan, sindrom atau pola ini seharusnya tidak hanya sekadar memunculkan respon atas suatu kejadian khusus seperti kematian orang yang dicintai. Gangguan dihubungkan dengan distress (tekanan), ketidakmampuan dalam hidup, atau risiko yang serius. Dengan kata lain, suatu gangguan meliputi masalah personal dan sosial" (Halgin \& Whitbourne, 2010).

$$
\text { Semua orang pasti pernah }
$$
mengalami penyakit mental. Namun, biasanya seseorang baru akan menyadari dirinya sakit dan butuh bantuan setelah mengalami gejala yang parah. Penyakit mental adalah keadaan di mana kondisi mental yang buruk membuat individu tidak mampu menjalankan fungsinya dalam tatanan sosial. Penulis memiliki trauma fisik dan psikis yang tidak bisa diceritakan ke publik. Hal ini membuat penulis sangat rentan. Sementara dalam 4 tahun terakhir, penulis berjuang dengan penyakit kronis yang membuat penulis merasa terenggut kehidupannya. Bahkan sempat ada masa di mana penulis lumpuh dan tidak dapat berkomunikasi. Empat tahun dalam perjuangan dan tidak nampak hasil, membuat penulis jatuh dalam depresi psikotik. Depresi dalam jangka waktu lama, yang di dalamnya terdapat gejalagejala psikosis seperti halusinasi, delusi, tidak bisa membedakan kenyataan dan khayalan. Hal ini menimbulkan masalah baru: gejala psikosomatis. Keluhan fisik yang berasal dari kondisi mental yang buruk membuat penulis sempat makin terpuruk dan tidak bisa beraktivitas sama sekali. Dalam keadaan tidak ada harapan inilah yang menjadi pemicu dan inspirasi untuk melepaskan ketegangan yang dialami dalam seni lukis. Namun ternyata penulis hanyalah salah satu sampel dari sekian banyak variabel. Pengalaman pribadi ini memberikan pemahaman bahwa banyak teman-teman mahasiswa seni dan senior yang mengalami penyakit mental.

Memilih kuliah di ISI Yogyakarta menyadarkan penulis akan potensi seni rupa. Pemilihan penggunaan warna dan cara menggoreskan kuas mempengaruhi suasana hati dan pemikiran manusia. Terutama bagi si pencipta seni rupa yang melakukan proses kreatif tersebut. Sebagai mahasiswi yang memilih menekuni seni lukis, pengalaman yang mampat tersebut, tersalurkan dalam proses kreatif. Kegiatan menciptakan karya seni memiliki efek terapeutik. Sebuah katarsis (pelepasan) konflik internal.

Lewat visualisasi ide yang mempertimbangkan nilai-nilai artistik, pengungkapan pandangan dan pengalaman yang sifatnya pribadi akan menjadi menarik. Hal-hal yang tadinya bersifat subjektif mengalami pengolahan yang kemudian dihadirkan secara objektif. Elemen-elemen seni rupa yang digarap dengan baik dapat menjadi penarik perhatian audiens. Penggunaan warna, yang mendominasi pertimbangan teknis berkarya lukis dalam Tugas Akhir ini, akan membentuk suasana dalam menikmati karya lukis. Menghadirkan pengalaman yang seolah-olah milik audiens sendiri. Lewat pengalaman estetis yang berkesan bagi audiens, terinspirasi oleh Frida Kahlo, penulis ingin berbagi pengalaman. 
Karya seni dalam jurnal ini diharapkan memunculkan ruang dialog yang intim. Sehingga diskusi antar pengalaman dan pandangan, terpantik melalui karya seni. Ke depannya, semoga penulis dapat menghasilkan karya seni yang dapat mengubah pandangan dan stigma tentang hal-hal yang masih tabu atau jarang didiskusikan.

Berdasarkan latar belakang sebelumnya, ketertarikan penulis terhadap masalah penyakit mental yang diangkat dalam bentuk memoar seni lukis, maka permasalahan tugas akhir dirumuskan sebagai berikut:

1. Bagaimana memoar visual akan penyakit mental berpengaruh dalam penciptaan lukisan?

2. Bagaimana caranya mewujudkan pengalaman akan penyakit mental dalam lukisan?

\section{B. Konsep Penciptaan}

Konsep Penciptaan adalah landasan pemikiran, prinsip, tatanan, atau ide seorang seniman dalam menciptakan karya seni. Dalam prosesnya, ia dipengaruhi oleh banyak faktor: persepsi, perspektif, dan selera, contohnya. Semua faktor ini berasal dari pengalaman. Dari awal sejarah seni, seniman berkarya seni dari pengalamannya. Yakni apa yang diinderakan, apa yang dirasakan. Pengalaman membentuk persepsi. Persepsi membentuk citraan dalam karya seni.

Karya seni rupa dua dimensional yang menampilkan unsur warna, bidang, garis, bentuk, dan tekstur. Sebagai bagian dari seni murni, seni lukis merupakan Bahasa ungkapan pengalaman artistik dan ideologi (Bahari, 2008).

Pengalaman pribadi, yang mengalami proses pengolahan, memberi nilai-nilai yang menjadi ide dan tatanan dalam berkarya. Pengalaman pribadi individu adalah unik. Objek yang sama pun, ketika dialami lewat kemasan yang berbeda akan memberikan kesan yang berbeda. Sehingga menjadi pengalaman yang berbeda pula. Keunikan ini menjadi pokok dari yang hendak disampaikan seniman dalam karya seni.
Yakni menyampaikan apa yang subjektif dalam tatanan objektif.

Salvador Dali, contohnya. Pengalaman hidupnya yang unik membentuk kepribadiannya menjadi eksentrik. Keeksentrikannya tersebut, seringkali beririsan dengan gejala neurosis. Membawanya pada berbagai diagnosis penyakit mental. Ide-ide dari pengalaman gejala neurosisnya, mengalami transformasi ke dalam karya seni. Berbagai dorongan yang muncul dari pengalaman yang kuat, digubahnya dalam bentuk-bentuk tidak lazim. Karyanya menjadi surealis, sebab ia menggambar realitanya yang absurd. Subjektivitasnya ia hadirkan dalam lukisan. Dali hidup di masa yang sama dengan Freud, sehingga teori psikonalasis sangat berpengaruh dalam proses pengkaryaannya. Ia bahkan merasa bahwa lukisannya adalah hasil nyata, sebuah pembuktian, atas teori-teori alam bawah sadar Freud. Dali terus menerus membuat karya seni yang didasarkan persepsinya tersebut.

Seperti Dali, latar belakang pengalamanyang paling banyak mengilhami proses kreatif penulis adalah penyakit mental. Pengalaman ini berakar sangat kuat dan menjadi momentum bagi proses kreatif penulis. Otak seniman merupakan mimikri terhadap otak dengan gangguan kejiwaan.

"Some of the world's leading artists, writers and theorists have also had mental illnesses

- the Dutch painter Vincent van Gogh and American mathematician John Nash (portrayed by Russell Crowe in the film A Beautiful Mind) to name just two. Creativity is known to be associated with an increased risk of depression, schizophrenia and bipolar disorder "(www.bbc.com, 2019).

Kreativitas diketahui memiliki asosiasi dengan meningkatnya resiko depresi, skizofrenia, dan bipolar disorder. Karya seni rupa, dalam proses terjadinya, melibatkan imajinasi, fantasi, lamunan, angan, yang seringkali bersinggungan dengan gejala neurosis. Orang awam akan mengalami kesulitan untuk membedakan mana ide-ide yang berasal dari "kreativitas" 
dan mana yang berasal dari gejala neurosis. Sebab nanarnya batas antar keduanya.

Selain contoh-contoh tersebut, terdapat pula para psikiater yang menyetujui bahwa seniman rupa memiliki kemungkinan tinggi untuk terkena penyakit mental. Satu set kepribadian yang rentan terhadap penyakit mental, biasa ditemui pada seniman: sensitivitas dan perfeksionisme. Khayalan yang berlebihan, membaur dengan realita, menjadi salah satu tanda yang patut diwaspadai. Proses kreatif dan keadaan kejiwaan yang terganggu memiliki kaitan. Seni tercipta bukan sebagai respon, namunia ada sebagai output/hasil jadi dari gangguan yang telah ada sebelumnya. Baik gangguan tersebut disadari maupun tidak. Keduanya saling tarik-menarik (www.dailyartmagazine, 2019).

\section{Gagasan Karya}

Dari paparan pengalaman pribadi penulis tentang penyakit mental, kaitan antara kreativitas dan penyakit mental, bagaimana seni rupa menjadi sarana terapi atau pelegaan bagi ODMK, serta kecenderungan seniman untuk melakukan proses berkarya seni sebagai otobiografi, menjadi landasan bagaimana karya seni lukis penulis terwujud. Dinamika keseharian penyakit mental menjadi ide untukditranslasikandanditransformasikan menjadi karya seni. Penulis terinspirasi untuk menuangkan pengalaman penyakit mental secara gamblang dalam lukisan. Proses melukis memberikan wadah bagi penulis untuk menuangkan yang tidak dapat dituang ke tempat lain. Seniman, termasuk penulis, adalah pribadi yang sensitif dan seringkali menjadi romantis di saat yang bersamaan. Sensitivitas seniman sering membuat perasaan mendominasi ide dalam berkarya. Terutama apabila mengalami perasaan yang meluap-luap, seperti kesedihan yang sangat dalam atau kebahagiaan yang gegap gempita. Bagi penulis, pengalaman gejala neurosis yang intens adalah dorongan hebat untuk berkarya seni.

Semuakarya seni bersifat otobiografis karena merupakan cerminan dari kehidupan seniman (www.theupcoming. co.uk, 2018). Didukung juga pendapat dari Nunung W.S., salah satu seniman Indonesia. Karya adalah suatu pengalaman batin. Semua hal adalah pengalaman yang pernah dirasakan oleh batinnya. Seni bermuara dari diri sendiri (W.S.: 2008).

$$
\text { Pengalaman akan penyakit }
$$
mental adalah ide pokok yang hendak divisualisasikan oleh penulis. Pengalaman menjadi gagasan yang akan dihadirkan dari karya lukis. Tujuan dari proses berkarya adalah menuangkan dan menghadirkan pengalaman penyakit mental. Pengalaman penyakit mental akan hadir sebagai nuansa atau suasana yang dialami oleh audiens kemudian. Subjek yang dilukiskan adalah gejala dan keseharian dalam pengalaman tersebut. Sehingga penyakit mental menjadi periode memoar.

Dalam visualisasinya, penyakit mental sendiri sudah lekat dengan aliran surealisme. Gejala neurosis atau penyakit mental sangat banyak mengandung imajinasi dan fantasi yang nanar batasnya dengan realita. Contohnya, kerumunan orang yang tidak dapat dilihat wajahnya karena telah meleleh. Apabila pengalaman tersebut digambarkan apa adanya pun, sangat sarat dengan surealisme. Objek lukis yang digambarkan berasal dari realita, namun realita itu sendiri telah mengalami distorsi. Teknik realistis dengan warna-warna yang kusam, menjadi cerah dan kuat. Objek kehilangan ciri khususnya sehingga sulit diidentifikasi. Pengalaman-pengalaman semacam itu akan ditranslasikan langsung dalam visualisasi yang apa adanya. Namun, tidak seluruh gejala penyakit mentalpun seekstrim itu. Ada beberapa pengalaman yang hampir tidak terasa bahwa itu adalah gejala penyakit mental. Ada pula beberapa pengalaman yang terlalu ekstrim subjektivitasnya sehingga harus mengalami gubahan agar dapat menjadi ide yang relevan bagi audiens. Untuk pengalaman yang sifatnya lebih halus ini, penulis akan mentransformasikan ide sehingga menjadi penggambaran yang representatif. Yakni 
penggambaran yang memiliki nilai dan makna kiasan. Makna tambahan yang lebih dari sebagaimana yang terlihat.

Fungsi karya seni sebagai media katarsis juga berperan banyak dalam proses kreatif bagi penulis. Unsur bawah sadar dari penyakit mental, dimunculkan dalam kecenderungan berkarya yang intuitif dan menggunakan kaidah automatism. Kaidah berkesenian tersebut merupakan tonggak awal surealisme, di mana alam bawah sadar mengambil alih proses pengerjaan lukisan. Penggoresan kuas, pencipratan cat, atau segala usaha membuat elemen seni rupa, dilakukan dengan menekan alam sadar dan membiarkan alam bawah sadar mengambil alih. Hal ini memberikan citraan yang ekspresif, spontan, dan lugas. Dalam proses kreatif, penulis banyak menerima pengaruh referensi dan kritik yang membentuk identitas karya seninya.

Hal-hal eksternal tersebut mengalami berbagai pengolahan dalam perkuliahan sehingga membentuk pandangan pribadi dalam penggarapan lukisan. Terutama mengenai gaya melukis, yang merupakan ciri khas utama dari karya lukis. Pembuatan karya kemudian menjadi unik dan terbentuk struktur yang baik dalam proses kreatif.

\section{Konsep Visual}

Penulis ingin menyampaikan apa yang dirasakan (tangible) oleh penderita penyakit mental, lewat lukisan. Sehingga lukisan menjadi pemantik pengalaman. Karya seni, dapat menghadirkan momen estetis yang menjadi pemicu perasaan atau sensasi bagi audiens. Momen estetis yang ingin disampaikan penulis adalah pengalaman penyakit mental. Dengan audiens merasakan, telah mengalami proyeksi kehidupan seseorang dengan penyakit mental.

Penulis melukis menggunakan konsep abstrak dan abstraksi untuk bisa lebih fokus ke dalam penyampaian emosi dan perasaan. Agar bisa menjembatani dengan baik dari yang tidak dapat dirasakan (intangible) menjadi dapat dirasakan (tangible). Lukisan abstrak memiliki potensi paling baik untuk penyampaian emosi, karena terfokus pada pengolahan unsur-unsur seni rupa. Kemurnian bidang, garis, dan warna, memberikan wadah berekspresi yang tidak bisa dicapai kedalamannya oleh lukisan figuratif. Gaya melukis abstrak lebih fokus pada luapan dan estetika tentang perasaan dan alam bawah sadar. Sementara gaya melukis abstraksi, memberi kemudahan untuk mengaplikasikan penggambaran yang masih kaya akan ekspresi, namun memiliki garis bantu penyampaian ide yang lebih tegas. Abstraksi tidak hanya terpaku pada luapan emosional dalam berkarya.

Eksplorasi material dan teknik dilakukan agar menjadi bahasa visual yang ekspresif. Kemudian direspon dengan bentuk-bentuk organik. Spontanitas dan kelugasan menjadi yang utama untuk disampaikan dalam pengkaryaan. Dengan dominasi warna-warna fluorescent yang memiliki intensitas tinggi untuk penggambaran psikedelia dan warna-warna gelap untuk penggambaran suasana kelam dari penyakit mental.

Konsep abstrak yang digunakan pelukisadadiranahsenirepresentatif. Yakni, abstrak yang menggunakan elemen seni rupa sebagai simbol yang memiliki makna. Jackson Pollock (www.jackson-pollock. com, 2020) adalah salah satu seniman yang semasa hidupnya ikut memberikan sumbangsih kepada makna abstrak. Pada awalnya, ia menarasikan bahwa cipratan dalam karyanya, sebenarnya adalah hasil pengamatannya terhadap unsur alam; representatif. Hal ini pun dinyatakannya ketika telah terpengaruh oleh automatism Joan Miro. Yakni, ketika Jackson Pollock telah berkarya menggunakan intuisi dan elemen seni rupa. Namun, kemudian, ia melukiskan cipratan sebagai bentuk pembebasan dari pemahaman bahwa seni tidak harus diasosiasikan. Konsepnya akan abstrak, murni merupakan hasil ekspresi dari elemen seni rupa. Setelah itu pun, di penghujung hidupnya, ia kembali memfungsikan elemen seni rupa sebagai objek representatif dalam lukisannya. Sepanjang karirnya melukis abstrak, 
ia berusaha menemukan titik tengah antara abstrak yang dipahami sebagai pembebasan asosiasi, yakni abstrak non representatif, dengan abstrak yang masih menghormati asal idenya dari alam atau abstrak representatif (www.bbc.co.uk, 2020).

Banyak pelukis Indonesia yang menuangkan pengalaman tekanan batinnya ke dalam lukisan, salah satunya adalah Lucia Hartini. Beliau menggambar terinspirasi dari pengalaman katarsisnya melalui objek-objek alam. Alam memberikan kenangan yang melegakan kesedihan pada masa kanak-kanaknya, hal ini dituliskan oleh Astri Wright (1999) :

"More than anything, I loved watching the reflection of the sun in water. ... It always made me dream. And at night I was always dreaming about clouds with sunlight [on or behind them]. Or I would be watching the night moon, or the stars ... ah -- how I loved all that, from when I was a little girl... At that time, if I was crying or disturbed, naughty or sick, my older sisters who were babysitting me would take me outside to watch the lights at the top of Mount Sumbing. There were always lights there, shining from behind the mountain, like this - (sculpting rays of light in the air with her hands). Whenever I saw those lights, I would quiet down and become peaceful, right away".

Dari paparan konsep perwujudan, penulis menggunakan unsur seni rupa tertentu dalam visualisasi karya. Yakni garis (line), warna (color), bidang (shape), ruang (space), gelap-terang (value), dan tekstur (texture) (Madijono, 2019). Berikut penguraian unsur-unsur tersebut:

1. Garis (line)

Garis digunakan untuk memberi outline, memberi bentuk objek, dan menjadi bidang. Garis memiliki nilai ekspresi, sehingga penggunaannya banyak dieksplorasi dalam visualisasi karya.

2. Bidang (shape)

Bidang adalah konsep keruangan 2 dimensi. Bidang dalam seni rupa merupakan bagian yang mempunyai sisi lebar dan panjang. Bidang dibentuk dari pertemuan garis sehingga memiliki ruang di dalamnya (Madijono, 2019). Bidang dalam karya seni rupa dapat merupakan bidang yang teratur (geometris) dan tidak beraturan (organik). Bidang yang banyak digunakan adalah bidang organik untuk merespon spontanitas dalam eksplorasi teknik dan material.

3. Warna (color)

Warna yang dapat dipersepsikan oleh mata manusia merupakan penguraian dan pemantulan cahaya matahari terhadap objek. Pantulan yang berbeda-beda frekuensinya ini kemudian ditangkap oleh sel warna di dalam mata. Manusia melihat warna berupa penguraian gelombang cahaya.

4. Gelap-Terang (value)

Dalam seni lukis, gelap terang adalah konsep pemberian corak warna untuk memberikan nilai kedalaman dimensional. Gelap terang digunakan untuk memberikan definisi dan dimensi pada karya.

5. Tekstur (texture)

Tekstur dalam lukisan adalah permukaan yang dilihat dan dapat diraba. Kasar, halus, bening, kusam merupakan sifat permukaan dari suatu benda.

Tekstur yang digunakan adalah tekstur nyata dan semu. Penulis menggunakan tekstur nyata untuk memvisualisasikan bentuk yang tajam, ceruk, dan retakan.

Seluruh unsur dalam seni rupa, menjadi bahasa visual dan memberi makna yang menekankan permasalahan tertentu pada karya. Kadang suatu karya akan memiliki kecondongan pada beberapa unsur tertentu, untuk penyampaian ide yang lebih spesifik. Unsur-unsur ini digubah sedemikian rupa dalam desain, sehingga dapat menjadi penyampaian yang baik atas memoar penyakit mental.

\section{E. Proses Penciptaan}

Proses pembentukan merupakan tahapan pengolahan teknis karya. Dari ide hingga menjadi karya seni. Digunakan pemilihan bahan dan alat dalam proses. Kemudian diaplikasikan dengan teknik yang paling cocok. Sehingga antara ide dan hasil akhir karya menjadi sinergis. 


\section{Persiapan}

Pada tahap awal ini, dilakukan berbagai jenis persiapan untuk membuat karya seni yang baik. Hal yang paling pertama dilakukan adalah penyediaan alat dan bahan. Sebelum membeli alat dan bahan, penulis biasanya akan melakukan survei atau pengenalan lebih lanjut terlebih dahulu mengenai karakteristik alat dan bahan yang akan dipilih.

Pada tahap persiapan ini, penulis juga melakukan proses pemberian dasaran pada media yang akan dilukisi. Kanvas dibentangkan pada spanram dan dilakukan proses plamir.

\section{Perenungan (Incubation)}

Tahap inkubasi atau perenungan adalah tahap di mana penulis banyak mengolah ide dari inspirasi yang didapatkan. Inspirasi biasanya datang secara spontan dalam bentuk ilham pada penulis. Karena berupa ilham, ide biasanya tidak muncul sekejap setelah melihat suatu hal yang menginspirasi. Namun merupakan proses pengolahan bawah sadar tentang berbagai hal yang telah menginspirasi sebelumnya.

Pada tahap perenungan ini, sebelum kemunculan ilham, penulis mengkaji karya seni referensi untuk lebih memahami bagaimana karya seni terjadi di luar pengalaman penulis. Inspirasi (Inspiration). Pada tahap ini, dilakukan penuangan ide ke dalam bentuk sketsa. Sketsa banyak dilakukan menggunakan media digital. Yakni aplikasi handphone dan stylus (pena khusus untuk menggambar pada media digital). Aplikasi yang digunakan adalah MediBang Paint dan Color Reference. Keuntungan dari media digital adalah keringkasan. Inspirasi bisa datang di manapun dan kapanpun.

\section{Pemunculan (Insight)}

Insight atau pemunculan ide adalah tahapan di mana penulis mulai melaksanakan proses penciptaan karya. Tahap-tahap itu yakni pembuatan latar belakang, pelukisan objek 1, pelukisan objek 2 (proses pemberian detail), proses finishing, dan evaluasi.

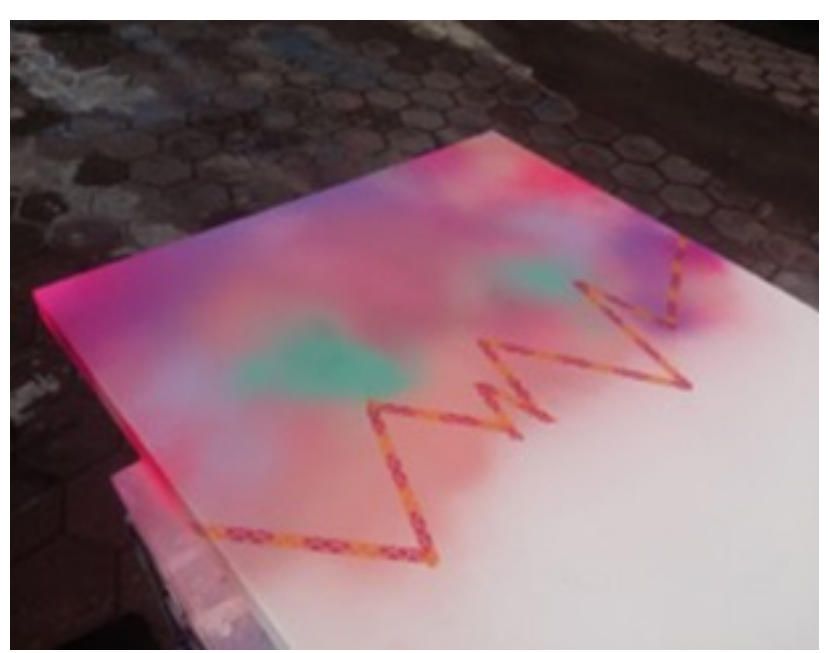

Gb. 01. Pembuatan latar belakang pada karya Bipolar Frenzy dengan teknik gradasi halus terlebih dahulu

Sumber: dokumentasi Elisa Faustina, 2020

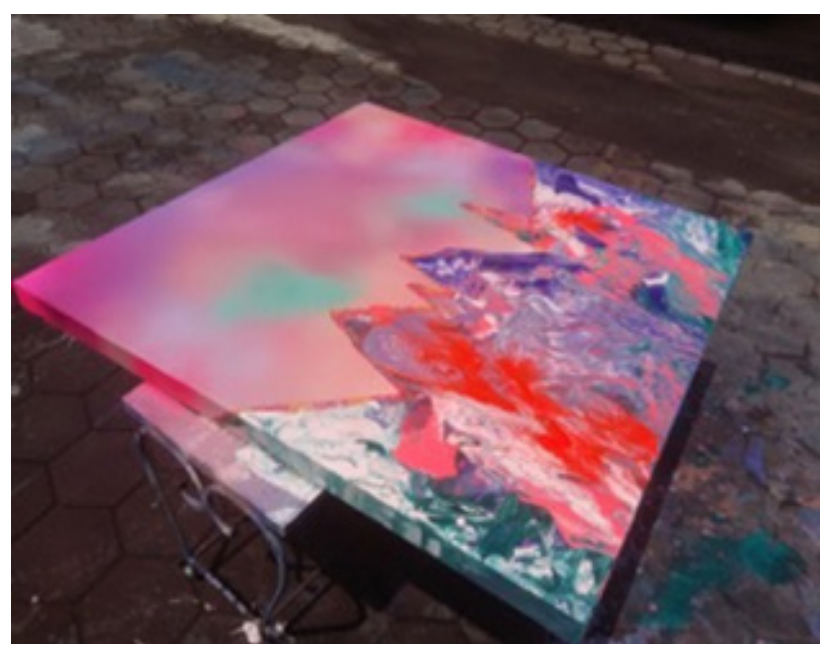

Gb. 02. Pembuatan latar belakang Bipolar Frenzy di tahapan teknik pour acrylic

Sumber: dokumentasi Elisa Faustina, 2020 


\section{E. Deskripsi Karya}

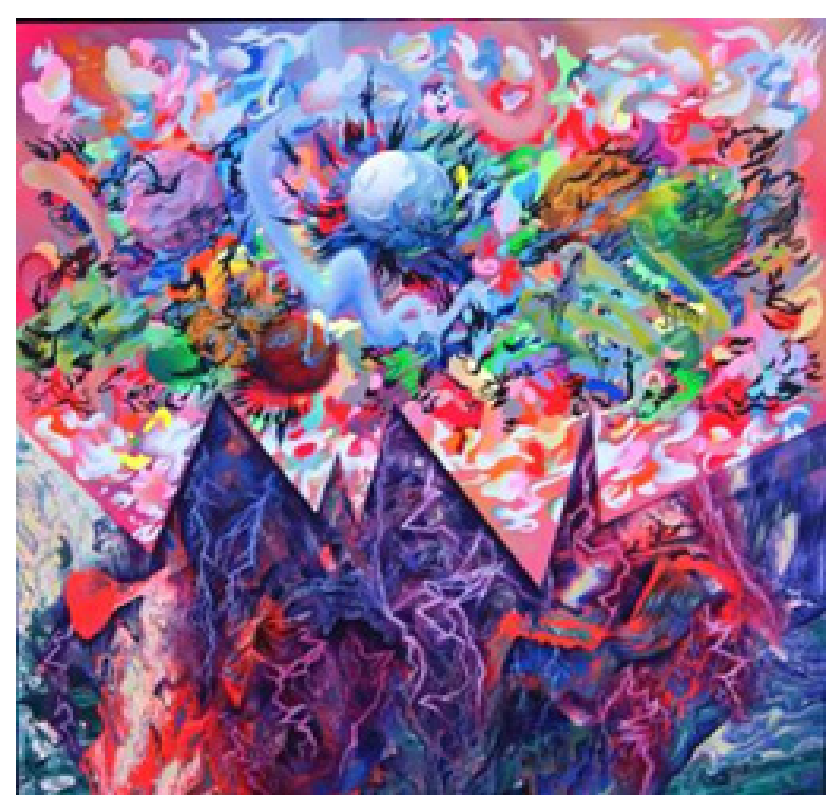

Gb. 03. Bipolar Frenzy, 2020

100 x 100 cm, Media Campuran di atas Kanvas

(Sumber: Dok. Elisa Faustina,2020)

Ide pokok dalam lukisan ini adalah kekacauan internal dari penderita bipolar disorder. Kekacauan (disorder) dicitrakan dalam lansekap pegunungan dan langit. Setiap orang memiliki pemahaman lansekap yang normal dan umum. Pemahaman normal tersebut dikacaukan dalam karya ini. Digambarkan daratan memiliki unsur langit. Sementara langit diisi macam-macam benda langit seperti di luar angkasa. Lansekap ini abnormal. Keanehan dalam penggambaran lansekap ini dimaksudkan sebagai absurditas yang dialami penderita bipolar.

Sesuai namanya, bipolar, yakni dua kutub. Penderita gangguan bipolar memiiki 2 kutub emosi yang ekstrim. Jarak ekstrim ini digambarkan lewat ceruk-ceruk tajam dari pegunungan. Kontur pegunungan seolah menampakkan garis grafik yang naik dan turunnya tajam.

Kekacauan internal meniadakan hari yang damai bagi penderita bipolar. Sangat banyak pasien penderita gangguan bipolar yang mengeluhkan perasaan kewalahan sebab ekstrimnya perubahan mood. Pengalaman kacau dan kewalahan ini digambarkan dalam kepadatan obyek. Pegunungan digunakan untuk menggambarkan fase hipo (rendah). Langit digunakan untuk menggambarkan fase mania (aktif, tinggi). Perasaan yang meluap-luap dan kewalahan dalam fase hipo, digambarkan dalam badai. Petir dan kilat berwarna-warni terjadi di darat. Ketika di langit pun, benda-benda langit pun digambarkan saling bertumpukan, padat, bertemu. Benda langit harusnya berada lebih tinggi dari langit. Di lansekap ini, dijadikan satu di dalam area langit. Ketinggian dalam jarak langit atmosfer Bumi dan langit luar angkasa, disatukan. Perasaan energetik (high/tinggi) ketika dalam fase mania, tidak terukur tingginya. Naik dan naik terus.

Karya ini dibuat pernuh objek dan ornamen, dengan penggunaan warnawarna yang sangat kuat dan cerah. Memiliki kesan naif dan dangkal (flat), namun di saat yang bersamaan penggunaan warna tersebut membuat audiens merasa bosan. Intensitas yang tinggi terlalu melelahkan. Perasaan "penuh" dari penderita gangguan bipolar adalah yang ingin dicapai lewat karya ini.

\section{G. Kesimpulan}

Penyakit mental menjadi tekanan yang secara naluriah membutuhkan penyaluran. Telah banyak seniman lukis yang berkarya dengan penyakit mental sebagai idenya. Bahkan membangun seluruh perjalanan berkeseniannya berdasarkan ide-ide dari pengalaman penyakit mentalnya. Mereka mengangkat penyakit mental sebagai ide, baik secara sadar dan tematik, maupun hanya karena kebutuhan pelegaan. Seluruh karya seni dapat bersifat otobiografis, karena merupakan cerminan dari berbagai faktor yang membentuk si seniman itu sendiri.

Lewat karya lukis, konflik internal dalam kehidupan seseorang yang biasanya dibungkus rapat, menjadi isu yang dapat didiskusikan. Selain penyakit mental yang masih tabu dan sedang marak upaya 
destigmatisasinya, aib dan isu - isu di ranah tabu juga banyak didiskusikan lewat seni. SARA, kekerasan seksual, kegagalan berumah tangga, dan sebagainya. Lukisan menjadi salah satu media pembebasan bagi nilai-nilai konvensional. Pengemasan ide dan gagasan secara kreatif melalui nilainilai estetika, memberikan pandangan dan pengalaman baru bagi audiens. Pengalaman ini kemudian memantik diskusi.

Melalui karya yang diciptakan ini, penulis ingin membagikan terjemahan pribadi atas pengalaman penyakit mental ke dalam lukisan. Menggunakan warna-warna dengan intensitas kuat yang mengganggu, serta bentuk-bentuk ganjil yang tidak masuk akal. Dari karya-karya tersebut, diharapkan audiens dapat ikut merasakan pengalaman penyakit mental. Sehingga pengalaman estetis yang didapatkan dari melihat karya-karya penulis dapat menjadi upaya destigmatisasi terhadap ODMK (Orang dengan Masalah Kesehatan Mental) atau orang-orang yang bermasalah dengan kehidupan dan memiliki konflik internal.

\section{Daftar Pustaka \\ Buku:}

Bahari, N. (2008). Kritik seni: wacana, apresiasi, dan kreasi. Pustaka Pelajar.

Halgin, R. P., \& Whitbourne, S. K. (2010). Psikologi abnormal: Perspektif klinis pada gangguan psikologis. Jakarta: Salemba Humanika.

Madijono, S. (2019). Mengenal Seni Rupa Murni. Mutiara Aksara.

Wright, A. (1999). Selftaught against the Grain: Three Artists and a Writer. EdsFlaudette

May Datuin andPatrick Flores, Women Imagining Women:Home, Body, Memory. Conference Proceedings. Manila, University of the Philippines Department of Art Studies, the Ford Foundation, Manila and the Cultural Center of the Philippines. W.S., Nunung, "Karya adalah Suatu
Pengalaman Batin", p. 193-198, 2006, Dalam Sulebar

M. Soekarman (Ed.). 2008, Seni Abstrak Indonesia:

Renungan, Perjalanan, dan Manifestasi Spiritual, Yayasan Seni Visual Indonesia, Jakarta

\section{Website:}

https://www.bbc.com/news/10154775, diakses penulis pada tanggal 20 Desember 2019, jam 20.04WIB

https://www.bbc.co.uk/programmes/artic les /5BNv7H97g3SpczrK56dHngF/ jackson-pollocks-forgotten-bleakmasterpieces-the-30-year-wait-forblack-pourings-exhibition, diakses penulis pada 30 November 2020 , jam 21:29 WIB

https://www.dailyartmagazine.com/ artists-who-suffered-mental-illness, diakses penulis pada tanggal 20 Desember 2019, jam 20.15WIB

https:/ /www.jackson-pollock.com/ biography.html, diakses penulis pada 30 November 2020, jam 20.38 WIB

https://observer.com/2015/07/a-masterof-reinvention-what-artists-canlearn-from-joan-miro-today/, diakses penulis pada 30 November 2020, jam 21.18 WIB , diakses penulis pada tanggal 27 Desember 2019, jam 7.15WIB

https://www.theupcoming. co.uk/2018/02/11if-all-artis-autobiographical-how-should-weapproach-it/, diakses penulis pada tanggal 29 November 2020, jam 14:47 WIB 